Article

\title{
TNF as Biomarker for Rapid Quantification of Active Staphylococcus Enterotoxin A in Food
}

\section{Reuven Rasooly * and Bradley Hernlem}

Western Regional Research Center, Agricultural Research Service, US Department of Agriculture, Albany, CA 94710, USA; E-Mail: bradley.hernlem@ars.usda.gov

* Author to whom correspondence should be addressed; E-Mail: reuven.rasooly@ars.usda.gov; Tel.: +1-510-559-6478; Fax: +1-510-559-6429.

Received: 3 March 2012; in revised form: 19 April 2012 / Accepted: 3 May 2012 /

Published: 10 May 2012

\begin{abstract}
Staphylococcus aureus is a major bacterial pathogen which causes clinical infections and food poisoning. This bacterium produces a group of twenty-one enterotoxins (SEs). These enterotoxins have two separate but related biological activities. They cause gastroenteritis and function as superantigens that activate large numbers of $\mathrm{T}$ cells. The current method for detection of enterotoxins activity is an in vivo monkey or kitten bioassay; however, this method is not practical to test on a large number of samples. Several immunological assays have been developed however, but these assays cannot distinguish between active toxin which causes food poisoning and inactive toxin, which can bind antibody, but shows no toxicity. The current study demonstrates that short term ex vivo exposure of primary naïve $\mathrm{CD}^{+}{ }^{+} \mathrm{T}$-cells or splenocytes to SEA induces differential expression and secretion of tumor necrosis factor (TNF) protein. We used immunomagnetic beads coated with anti-SEA antibody to specifically isolate SEA from food. After the eluted toxin was added to the cells SEA biological activity was measured by quantifying TNF protein expression or secretion.
\end{abstract}

Keywords: enterotoxin; food poisoning; TNF; immunomagnetic beads

\section{Introduction}

Staphylococcus aureus is one of the major bacterial pathogens causing clinical infections and foodborne illnesses [1]. This bacterium produces about 50 virulence factors that have a wide range of 
biological activities [2], including a group of twenty-one known enterotoxins (SEs) that act at very low concentrations and have two different, but related, biological activities; emetic activity and superantigenic activity [3-5]. SEs act on the gastrointestinal tract, and as a superantigen (SAg) on the immune system. Unlike normal antigens, SAg can bind to MHC class II molecules, which are expressed on the surface of a subtype of $\mathrm{CD}^{+} \mathrm{T}$ cells [6,7], which perform the role of both antigen presenting cell (APC) and $\mathrm{T}$ cell receptor (TCR). Therefore CD4+ T cells are able to present SAg to themselves or to neighboring $\mathrm{CD}^{+} \mathrm{T}$ cells without a safety mechanism which requires interaction between two types of cells [7]. This stimulates $\sim 20 \%$ of the naïve T-cell population which all share particular sequences within the variable region of the $\beta$ chain $(\mathrm{V}-\beta)$ of the T cell receptor (TCR) [8]. The current test to detect active SEs is an in vivo monkey or kitten bioassay $[9,10]$. This procedure has low sensitivity and poor reproducibility and requires many experimental animals. Immunological assays have been developed for several SEs, but these methods cannot distinguish between active and inactive toxin. Recent contamination with SEA causing an extensive outbreak with 13,420 cases in Japan [11,12], emphasizes the need to develop better methods to detect active SEs. In this work we used three complimentary approaches for measuring tumor necrosis factor (TNF). Differential expression of TNF was secreted in large quantities following short term ex vivo exposure to SEA therefore; TNF can be used as a biomarker for early detection of biologically active SEA in food.

\section{Experimental Section}

\subsection{Splenocyte Isolation}

Spleen cells from C57BL/6 female mice were prepared aseptically and disrupted using a syringe and needle in Russ-10 cell culture medium [made by combining $450 \mathrm{~mL}$ of RPMI 1,640 medium without glutamine (Gibco, Carlsbad, CA, USA), $50 \mathrm{~mL}$ Fetal bovine serum (Hyclone, Logan, UT, USA), $5 \mathrm{~mL} 200 \mathrm{mM}$ glutamine (Gibco), $5 \mathrm{~mL}$ antibiotic-antimycotic (Gibco-containing penicillin, streptomycin, and fungizone), $5 \mathrm{~mL}$ non-essential amino acid mix (Gibco), $5 \mathrm{~mL}$ sodium pyruvate (Gibco), and $0.25 \mathrm{ml}$ of $100 \mathrm{mM} \beta$-mercaptoethanol (Sigma, St. Louis, MO, USA). Cells were centrifuged at $200 \times \mathrm{g}$ at $4{ }^{\circ} \mathrm{C}$ for $10 \mathrm{~min}$. Red blood cells were then lysed by adding red cell lysis buffer $\left(0.15 \mathrm{M} \mathrm{NH}_{4} \mathrm{Cl}, 10 \mathrm{mM} \mathrm{KHCO}_{3}, 0.1 \mathrm{mM} \mathrm{Na} 2 \mathrm{EDTA}\right)$. Cells were again centrifuged and resuspended in Russ-10 medium, and viable cells were counted using trypan blue and a hemocytometer.

\subsection{Splenocyte Proliferation Assay}

Cells were placed in 96-well plates $\left(1 \times 10^{6} / \mathrm{mL}, 0.2 \mathrm{~mL}\right)$ in Russ-10 medium and treated with various concentrations of SEA followed by incubation at $37{ }^{\circ} \mathrm{C}$ in a $5 \% \mathrm{CO}_{2}$ incubator. After incubation at various time points, cell proliferation was measured by adding 5-bromo-2-deoxyuridine (BrdU)-labeled DNA to each well $4 \mathrm{~h}$ before fixation as described by manufacturer's instructions (Calbiochem, San Diego, CA, USA). Spectroscopic measurements were made of optical density at $620 \mathrm{~nm}$ and $450 \mathrm{~nm}$. 


\subsection{Positive Isolation of Murine $C D 4^{+}$T cells}

Murine $\mathrm{CD}^{+} \mathrm{T}$ cells were isolated using a positive selection (Dynabeads Mouse CD4 L3T4), according to the manufacturer's instructions. Briefly, Splenocytes were resuspended in isolation buffer (PBS supplemented with $0.1 \%$ BSA and $2 \mathrm{mM}$ EDTA) at a concentration of $1 \times 10^{7} / \mathrm{mL}$ and incubated with washed Dynabeads ( $25 \mu \mathrm{L}$ of Dynabeads per $10^{7}$ cells) for $20 \mathrm{~min}$ on ice with gentle rotation. After incubation, cells and Dynabeads were placed on a magnet for $2 \mathrm{~min}$. The supernatant was removed and the bead-bound cells were washed 3 times with isolation buffer. The bead-bound cells were resuspended in RUSS- 10 media $\left(10^{7}\right.$ cells per $100 \mu \mathrm{L}$ of media) and DETACHaBEAD mouse CD4 was added $\left(10 \mu \mathrm{L}\right.$ per $10^{7}$ cells) and incubated for $45 \mathrm{~min}$ with gentle rotation at room temperature. The detached beads were washed 3 times and resuspended in media.

\subsection{Coating Magnetic Beads with Anti-SEA Antibody}

One hundred $\mu \mathrm{L}$ of Dynabeads M-280 tosylactivated (Invitrogen, Carlsbad, CA, USA) were washed twice with $600 \mu \mathrm{L}$ of $0.1 \mathrm{M}$ sodium borate buffer, $\mathrm{pH} 9.5$, and diluted in the same buffer to $2 \times 10^{9}$ beads $/ \mathrm{mL}$. Purified anti-SEA antibody $(30 \mu \mathrm{g})$ was added to $1 \times 10^{8}$ beads $(50 \mu \mathrm{L})$. The antibody and beads were incubated for $24 \mathrm{~h}$ at $37{ }^{\circ} \mathrm{C}$ on a slow shaker to facilitate covalent binding. The coated beads were washed twice for $5 \mathrm{~min}$ at $4{ }^{\circ} \mathrm{C}$ with $1 \mathrm{~mL}$ phosphate-buffered saline (PBS), $\mathrm{pH} 7.4$, containing $0.1 \%$ bovine serum albumin (BSA), washed once for $4 \mathrm{~h}$ at $37{ }^{\circ} \mathrm{C}$ with $0.2 \mathrm{M}$ Tris- $\mathrm{HCl}$, $\mathrm{pH} 8.5$, containing $0.1 \% \mathrm{BSA}$, and washed once more for 5 min at $4{ }^{\circ} \mathrm{C}$ with $\mathrm{PBS}, \mathrm{pH} 7.4$, containing $0.1 \%$ BSA. The beads were resuspended in $50 \mu \mathrm{L}$ of the Tris-BSA buffer.

\subsection{Sample Preparation of Food}

Our preliminary result suggested that the food matrices themselves are somewhat cytotoxic, thus interferes with analytical outcomes. To overcome this obstacle the food were diluted; $20 \mathrm{~g}$ of each preserved chicken or green beans peas (Gerber) were added to $20 \mathrm{~mL}$ of PBS. Then the foods were spiked with $5 \mu \mathrm{g} / \mathrm{mL}, 1 \mu \mathrm{g} / \mathrm{mL}, 200 \mathrm{ng} / \mathrm{mL}, 5 \mathrm{ng} / \mathrm{mL}$ or $1 \mathrm{ng} / \mathrm{mL}$ of SEA.

\subsection{Sample Binding and Disassociation of SEA from Beads}

Fifteen $\mu \mathrm{L}$ of the immunomagnetic beads were incubated with a tilting motion at $4{ }^{\circ} \mathrm{C}$ with $1 \mathrm{~mL}$ of spiked green bean or chicken. After $24 \mathrm{~h}$, the tube was placed on a magnet for 2 min to collect the beads. The beads were washed twice with PBS, $\mathrm{pH} 7.4$, containing $0.1 \%$ BSA. Toxin was eluted with $7.5 \mu \mathrm{L}$ of $100 \mathrm{mM}$ glycine $\mathrm{HCl}(\mathrm{pH} 2.5)$ then neutralized with $7.5 \mu \mathrm{L}$ of $2 \mathrm{X}$ tris buffered saline (TBS) ( $\mathrm{pH} 8.3)$.

\subsection{Measurement of TNF by Cytometric Bead Array}

TNF concentration in cellular supernatant was assayed using Mouse Cytometric Bead kit (BD Biosciences, San Diego, CA, USA), following manufacturer's protocol. 


\subsection{Measurement of Intracellular TNF Protein Levels}

Cells were fixed and permeabilized following the procedure of BD kit Cat \# 555028. Intracellular staining of TNF with an APC anti-TNF antibody was performed following manufacture's protocol (BD Pharmingen, San Diego, CA, USA).

\subsection{Measurement of TNF by ELISA}

TNF concentration in cellular supernatant was measured using BD OptEIA mouse TNF ELISA Set (BD Biosciences), following manufacture's protocol.

\section{Results}

\subsection{Measuring Biologically Active SEA in Food by Splenocyte Proliferation Assay}

To evaluate the ability of the splenocyte proliferation assay to quantify specific SEs in chicken and green beans, we spiked these food products with increasing concentrations of SEA and then extracted the toxin by using immunomagnetic beads coated with anti-SEA antibody. Our result (Figure 1) shows that by measurement of incorporated BrdU into cellular DNA, toxin cannot be detected at day 1; it can be detected at day 3 . We also noticed that at day 3 there is a correlation between eluted SEA concentrations and cell proliferation.

Figure 1. Detection and quantify of SEA in food using BrdU cell proliferation assay. Chicken and green beans were spiked with increasing concentrations of SEA. Immunomagnetic beads were used to extract the toxin. Eluted toxin from beads was incubated with splenocytes. Proliferation was measured by incorporation of BrdU in newly synthesized DNA. Error bars represent standard error $(\mathrm{N}=7)$.

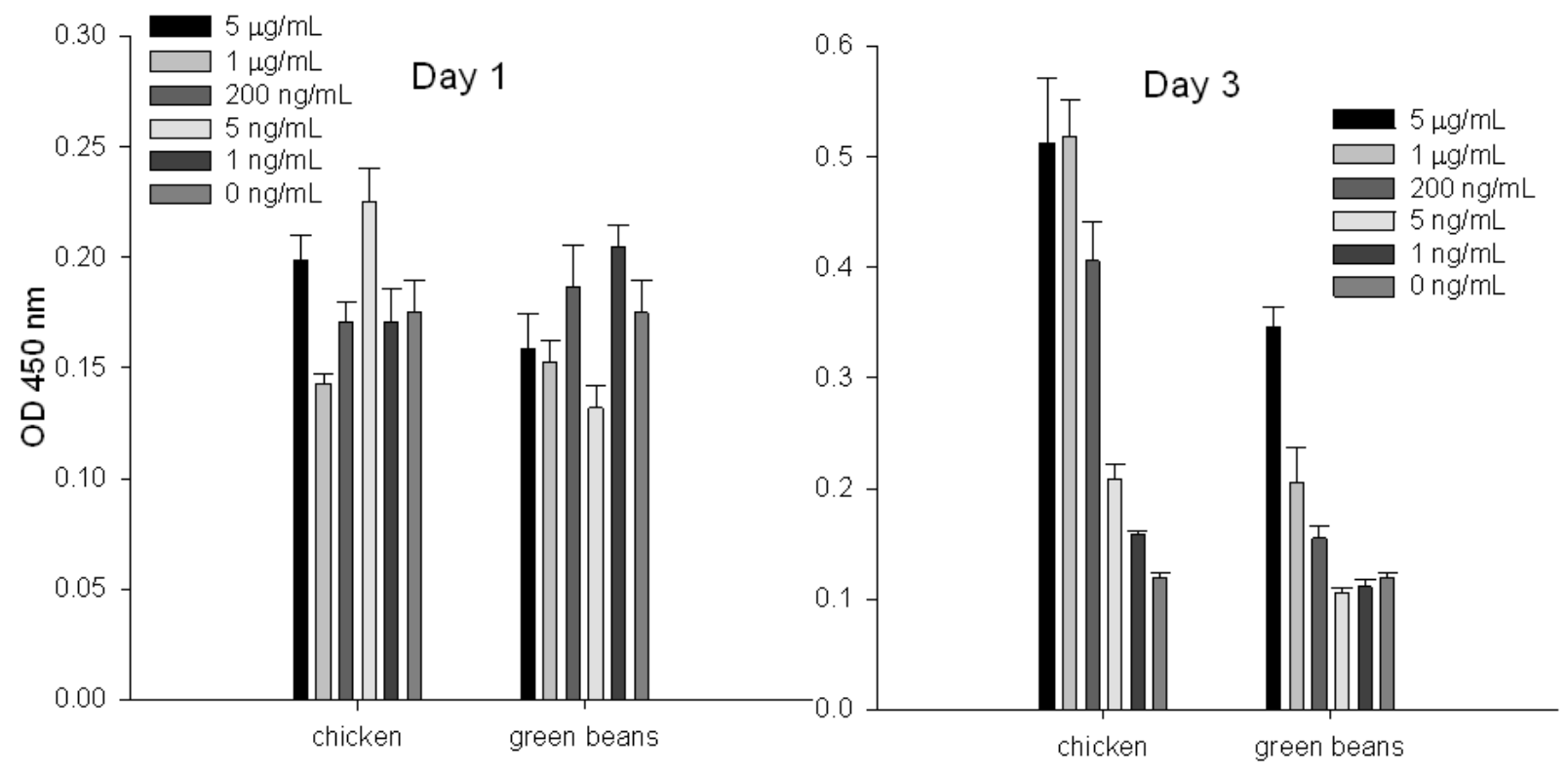




\subsection{Intracellular TNF Protein Expression for Detection of Biologically Active SEA}

Our preliminary results suggested that short term SEA stimulation of primary naïve CD4 ${ }^{+}$T-cells increases TNF expression. In order to develop biomarkers for early detection of active SEA we stimulated naïve $\mathrm{CD}^{+}{ }^{+} \mathrm{T}$-cells with SEA for $24 \mathrm{~h}$ and $48 \mathrm{~h}$. After intracellular staining, kinetic TNF production was assessed by flow cytometry. Our flow cytometric analysis shows (Figure 2) that SEA exposure increases the percent of cells that expressed TNF. The data also show that the production of TNF increased over time and that SEA can be detected at a concentration of $1 \mathrm{ng} / \mathrm{mL}$ after $24 \mathrm{~h}$.

Figure 2. Intracellular TNF protein accumulation level within $\mathrm{T}$ cells for detection of biologically active SEA. CD4 ${ }^{+}$T-cells were stimulated with $1 \mathrm{ng} / \mathrm{mL}$ of SEA for $24 \mathrm{~h}$ and $48 \mathrm{~h}$. Brefeldin A is added to prevent TNF secretion from the cells. The cells were fixed, permeabilized and stained with antibody against TNF. Flow cytometric analysis was used to measure TNF production by the cells.
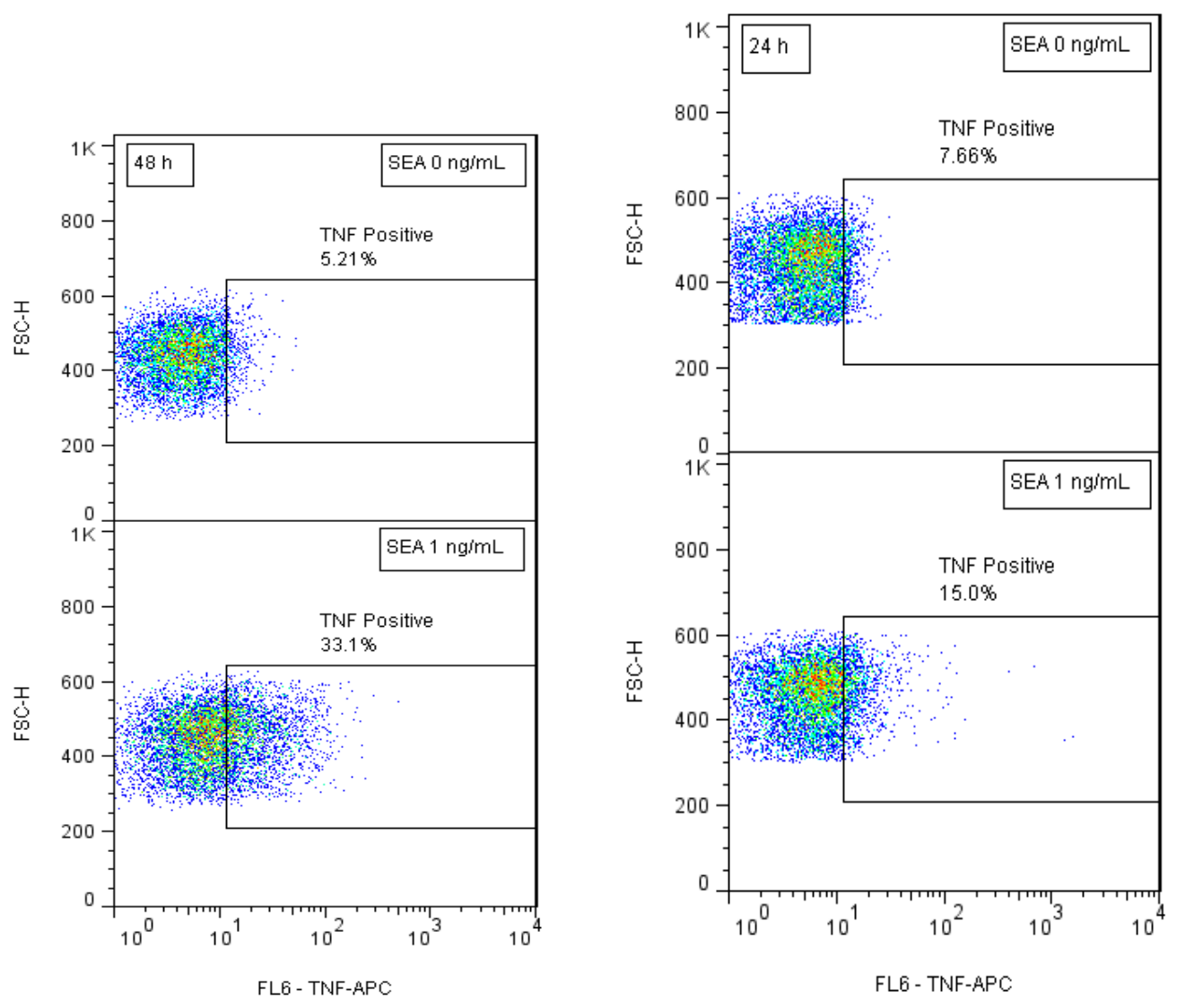

\subsection{Stimulation with SEA Induces Differential Protein Expression of TNF}

To assess whether short term stimulation will induce differential secreted TNF following SEA treatment, we incubated primary naïve $\mathrm{CD} 4^{+} \mathrm{T}$-cells or splenocytes with increasing concentrations of SEA. TNF protein secretion was analyzed on a FACSVantage SE Flow Cytometer. Our results (Figure 3) show that ex vivo SEA stimulation of primary naïve $\mathrm{CD} 4^{+} \mathrm{T}$-cells or splenocytes induces TNF protein secretion in a dose dependent response after $24 \mathrm{~h}$. 
Figure 3. Flow cytometric analysis for quantification of biologically active SEA. Primary naïve $\mathrm{CD} 4^{+} \mathrm{T}$-cells or splenocytes were spiked with increasing concentrations of SEA. After $24 \mathrm{~h}$ or $48 \mathrm{~h}$ of stimulation with SEA, TNF protein secretion was measured by flow cytometry.
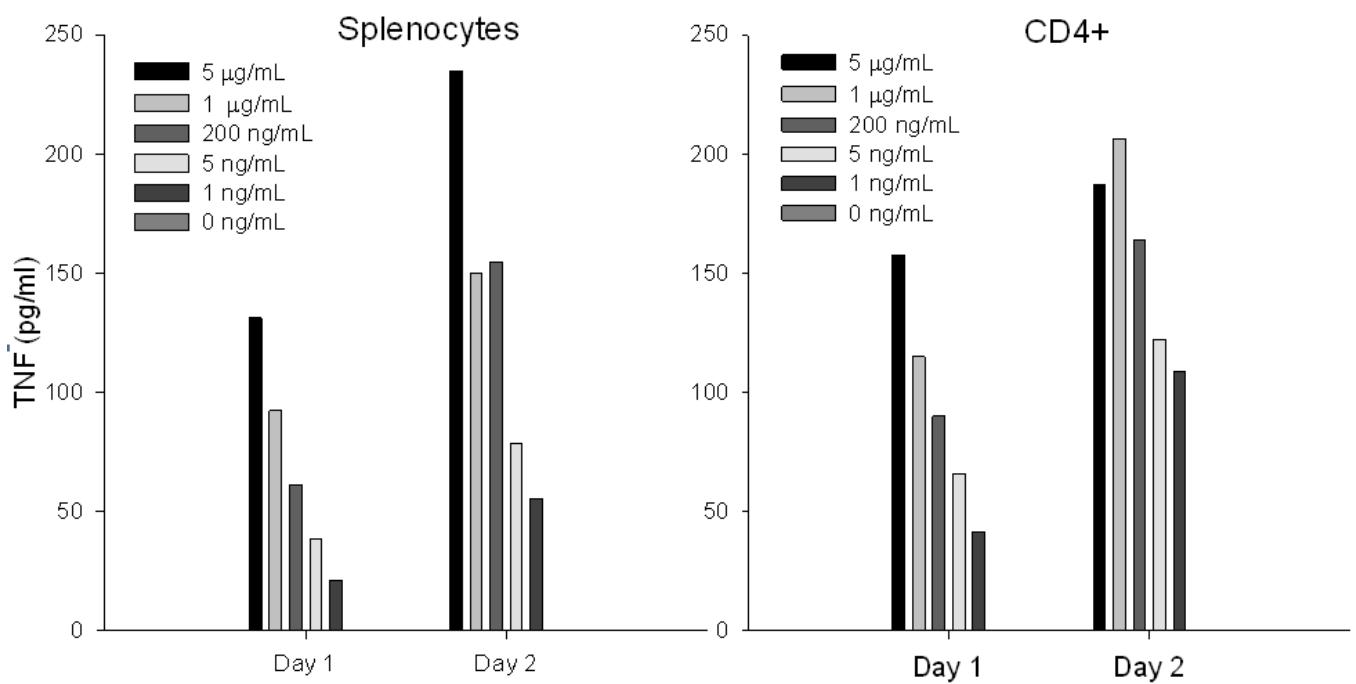

\subsection{Early Detection of Biologically Active SEA in Food by ELISA}

To evaluate if TNF protein secretion from splenocyte cells can be used for early detection and quantification of specific SEs in food, chicken and green beans were spiked with increasing concentrations of SEA. The toxin was extracted with immunomagnetic beads coated with anti-SEA antibody. The eluted toxin was incubated with splenocyte cells for $24 \mathrm{~h}$. The ELISA data show (Figure 4) that toxin extracted from food can be detected after $24 \mathrm{~h}$.

Figure 4. Quantification of biologically active SEA in food using ELISA assay. Chicken and green beans were spiked with increasing concentrations of SEA. Immunomagnetic beads were used to extract the toxin. Eluted toxin from beads was incubated with splenocytes. TNF secretion was measured by ELISA assay. Error bars represent standard error.

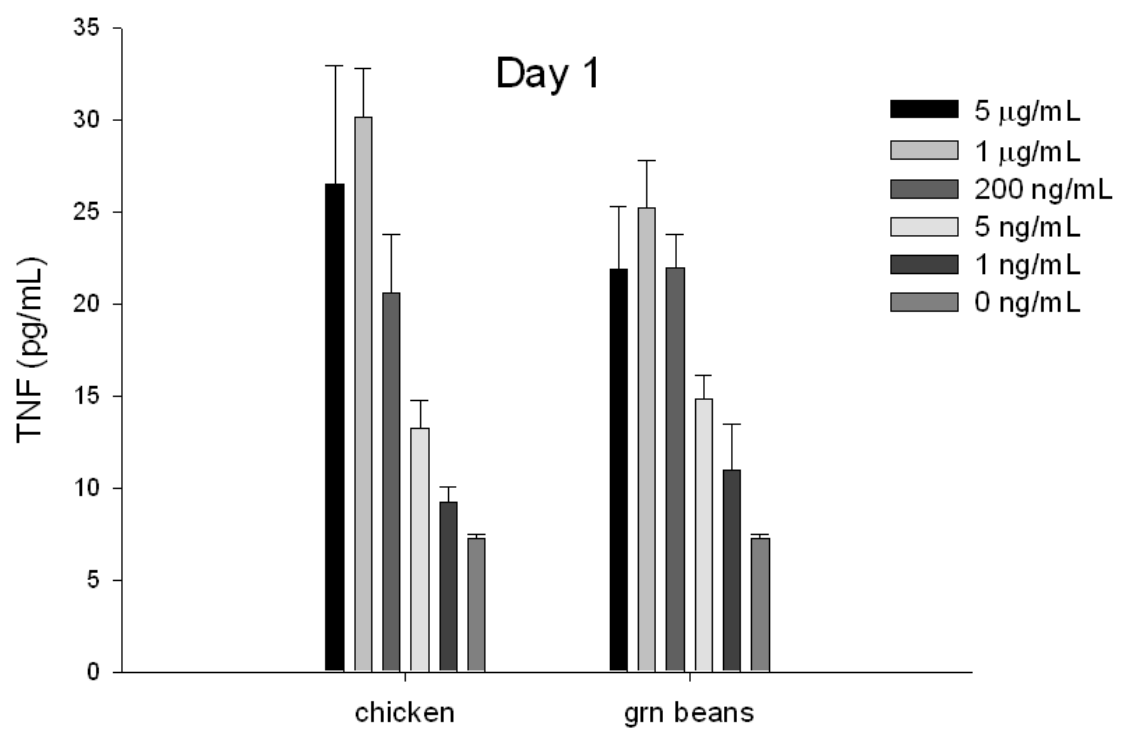




\section{Discussion}

In the present study, we evaluated a potential alternative method to the complex monkey or kitten bioassays for measuring biological activity of SEs. Here, we combined several approaches to detect and to quantify specific active SEs. We used SEA, which is associated with $75 \%$ of food borne staphylococcal outbreaks [13] and immunomagnetic beads coated with anti-SEA antibody to extract specific SEs from food. The cell proliferation assay, which measures incorporated BrdU into cellular DNA, is very sensitive with good reproducibility. However, the assay is time-consuming requiring several days of treatment with the toxin. In this work, we found that TNF represents an early molecular response or biomarker to SEA. TNF expression and secretion can be detected in less than $24 \mathrm{~h}$. We used two different flow cytometric analyses for quantitative measurement of TNF: cytometric bead array that quantifies TNF protein secretion and quantitative intracellular TNF accumulation. To detect TNF protein accumulation within $\mathrm{CD}^{+}$T-cells, Brefeldin A was added to prevent TNF secretion. The cells were then fixed, permeabilized, stained with APC- conjugated anti-TNF antibody and analyzed by flow cytometry. Although our flow cytometric results were rapid and sensitive, using this analysis requires expensive equipment and skilled personnel. To overcome this aspect, we used an ELISA test that is relatively simple, inexpensive and practical for testing a large number of samples. The results demonstrated that the immunology techniques tested; bead array, intracellular TNF accumulation, and the ELISA test can detect active SEA with the same sensitivity as the cell proliferation assay. Induction of TNF secretion by SEA is $48 \mathrm{~h}$ faster than by cell proliferation. By using three independent approaches to measure TNF, the cited data suggest that TNF is an early molecular response to SEA and is differentially expressed after a short term exposure. Therefore TNF can be used for early toxin detection in food.

\section{Acknowledgments}

We deeply thank Daphne Tamar and Sharon Abigail for helpful discussions.

\section{References}

1. Dinges, M.M.; Orwin, P.M.; Schlievert, P.M. Exotoxins of staphylococcus aureus. Clin. Microbiol. Rev. 2000, 13, 16-34.

2. Cheung, A.L.; Projan, S.J.; Gresham, H. The Genomic aspect of virulence, sepsis, and resistance to killing mechanisms in staphylococcus aureus. Curr. Infect. Dis. Rep. 2002, 4, 400-410.

3. Hui, J.; Cao, Y.; Xiao, F.; Zhang, J.; Li, H.; Hu, F. Staphylococcus aureus enterotoxin C2 mutants: Biological activity assay in vitro. J. Ind. Microbiol. Biotechnol. 2008, 35, 975-980.

4. Hu, D.L.; Omoe, K.; Sashinami, H.; Shinagawa, K.; Nakane, A. Immunization with a nontoxic mutant of staphylococcal enterotoxin A, SEAD227A, protects against enterotoxin-induced emesis in house musk shrews. J. Infect. Dis. 2009, 199, 302-310.

5. Harris, T.O.; Grossman, D.; Kappler, J.W.; Marrack, P.; Rich, R.R.; Betley, M.J. Lack of complete correlation between emetic and T-cell-stimulatory activities of staphylococcal enterotoxins. Infect. Immun. 1993, 61, 3175-3183. 
6. Reizis, B.; Schramm, C.; Cohen, I.R.; Mor, F. Expression of major histocompatibility complex class II molecules in rat T cells. Eur. J. Immunol. 1994, 24, 2796-2802.

7. Rasooly, R.; Do, P.M.; Hernlem, B.J. Auto-presentation of Staphylococcal enterotoxin A by mouse CD4 ${ }^{+}$T cells. Open J. Immunol. 2011, 1, 8-14.

8. Rasooly, R.; Do, P.M. In vitro cell-based assay for activity analysis of staphylococcal enterotoxin $\mathrm{A}$ in food. FEMS Immunol Med. Microbiol. 2009, 56, 172-178.

9. Bergdoll, M.S. Monkey feeding test for staphylococcal enterotoxin. Meth. Enzymol 1988, 165, 324-333.

10. Bennett, R.W. Staphylococcal enterotoxin and its rapid identification in foods by enzyme-linked immunosorbent assay-based methodology. J. Food Prot. 2005, 68, 1264-1270.

11. Asao, T.; Kumeda, Y.; Kawai T.; Shibata, T.; Oda, H.; Haruki, K.; Nakazawa, H.; Kozaki, S. An extensive outbreak of staphylococcal food poisoning due to low-fat milk in Japan: estimation of enterotoxin $\mathrm{A}$ in the incriminated milk and powdered skim milk. Epidemiol. Infect. 2003, 130, $33-40$.

12. Ikeda, T.; Tamate, N.; Yamaguchi, K.; Makino, S. Mass outbreak of food poisoning disease caused by small amounts of staphylococcal enterotoxins A and H. Appl. Environ. Microbiol. 2005, 71, 2793-2795.

13. Vernozy-Rozand, C.; Mazuy-Cruchaudet, C.; Bavai, C.; Richard, Y. Comparison of three immunological methods for detecting staphylococcal enterotoxins from food. Lett. Appl. Microbiol. 2004, 39, 490-494.

(C) 2012 by the authors; licensee MDPI, Basel, Switzerland. This article is an open access article distributed under the terms and conditions of the Creative Commons Attribution license (http://creativecommons.org/licenses/by/3.0/). 